\title{
Obesity: A New Adverse Effect of Antibiotics?
}

\section{Fernando S. Del Fiol'1*, Victor M. Balcão ${ }^{2}$, Silvio Barberato-Fillho', Luciane C. Lopes ${ }^{1}$ and Cristiane C. Bergamaschi'}

\author{
1 Seriema - Evidence Service for Monitoring and Evaluation, University of Sorocaba, Sorocaba, Brazil, ${ }^{2}$ PhageLab - \\ Laboratory of Biofilms and Bacteriophages of UNISO, $i(\mathrm{bs})^{2}-$ Intelligent Biosensing and Biomolecule Stabilization Research \\ Group, University of Sorocaba, Sorocaba, Brazil
}

Since the introduction of antibiotics, they have been used freely, with their prescription occurring almost always when they were not necessary. The other major form of contact between humans and antibiotics, now unintentionally, is with the large amount of these drugs in the environment and in our food. The relationship between antibiotic use and the development of obesity has become increasingly evident and apparent in humans, with some authors clearly establishing the relationship between the large-scale use of antibiotics in the past 70 years and the "epidemic" of obesity that has occurred in parallel, almost as an adverse epidemiological effect. In the research effort entertained herein, a correlation between the use and abuse of antibiotics and the onset of obesity was investigated.

\section{OPEN ACCESS}

Edited by:

Jean-Paul Deslypere,

Besins Healthcare, Thailand

Reviewed by:

Domenico Criscuolo,

Genovax S.r.l., Italy

Dominique J. Dubois,

Free University of Brussels, Belgium

${ }^{*}$ Correspondence:

Fernando S. Del Fiol

fernando.fio@@prof.uniso.br

Specialty section

This article was submitted to Pharmaceutical Medicine and Outcomes Research,

a section of the journal

Frontiers in Pharmacology

Received: 09 August 2017 Accepted: 16 November 2018 Published: 03 December 2018

Citation:

Del Fiol FS, Balcão VM, Barberato-Fillho S, Lopes LC and Bergamaschi CC (2018) Obesity: A New Adverse Effect of Antibiotics? Front. Pharmacol. 9:1408. doi: 10.3389/fphar.2018.01408
Keywords: obesity, antibiotics adverse effects, dysbiosis, gut microbiota, antimicrobial

\section{INTRODUCTION}

The introduction of antibiotics into clinical practice almost 70 years ago was, without a shadow of a doubt, the greatest therapeutic change in medical history, significantly altering mortality and morbidity indicators related to infections. "Magical bullets" have long been considered the Holy Graal for healing infections, but time has shown that we were wrong (Zaffiri et al., 2012).

Since the introduction of antibiotics, they have been used freely, with their prescription occurring almost always when they were not necessary. Recent data from the Centers for Disease Control and Prevention (CDC) shows that, 4 out of 10 children taken to a doctor's office with a common cold received antibiotics, certainly without necessity (Kronman et al., 2014).

Since their introduction into clinical practice, almost 80 years ago, millions of tons of antibiotics have been produced and used, almost always prophylactically, in cleaning products, cosmetics, etc., The use in veterinary medicine is even more significant, corresponding to $75 \%$ of all the antibiotics produced in the American market (Fauci and Marston, 2014). Beyond the exaggerated clinical use in children, we are still exposed to significant amounts of antibiotics in the water we drink (Donoghue, 2003; Yang and Carlson, 2003; Andersson and Hughes, 2014; Venkatesan and Halden, 2014) and even before we are born. A Danish study evaluated about one million of pregnant women and about one-third of them were exposed to one or more systemic treatments with antibiotics during their gestational period (Broe et al., 2014).

Cox and Blaser (2015), in an important study published in 2015, evaluating almost $70 \%$ of all pharmaceutical prescriptions made in 2010 in the United States; show that American children, on average up to 2 years of age, received three full medications with antibiotics. Ten full antibiotic medications up to 10 years and around 17 full antibiotic medications until they turned 20 years of age (Cox and Blaser, 2015). 
Despite both the abundant literature and information on the inefficacy of antibiotics in fighting viral infections, studies continue to show that the use of antibiotics in combating viral respiratory infections remains high. Ebell and Radke (2015) evaluated ca. 55000 visits of physicians by patients, presumably with ARTI (acute respiratory tract infections). The results showed that $49 \%$ of the patients with ARTI received prescriptions containing antibiotics; $8.9 \%$ of the patients received within 28 days a second prescription containing one antibiotic, and an astonishing $0.7 \%$ of the patients received a prescription with a third antibiotic to treat a viral infection (Ebell and Radke, 2015).

In a study published in Japan, the authors investigated almost 25,000 medical appointments related to upper respiratory tract infections, with no indication of bacterial etiology. The authors reported that antibiotics were prescribed in $60 \%$ of the appointments, with third-generation cephalosporins predominating among the antibiotics prescribed for these infections of viral etiology (Higashi and Fukuhara, 2009).

In a study published in 2014, the authors showed that more than half (51\%) of the patients with cough/cold diagnoses received antibiotic prescriptions by general practitioners in the United Kingdom in the year 2011. Using the same methodology, the authors of the study demonstrated that in 1999 such percentage was much lower (36\%) (Hawker et al., 2014).

Despite all the scientific literature, as well as International associations such as the World Health Organization, being emphatic in the guidelines for decreasing the number of antibiotic prescriptions and, when necessary, prescribing them in a more rational way (Cima, 2014), the numbers and studies continue to show an exaggerated use of these medicines, especially in children.

The other major form of contact we have had with antibiotics, now unintentionally, is with the large amount of these drugs both in the environment and in our food.

It is well known that the use of antibiotics in the production of animal proteins (cattle, pigs, and chickens) has been taking place since the 1940s, dumping thousands of tons of antibiotics into the feed of these animals. In the 1940s, Moore et al. published an article stating that sulfadiazines and aminoglycosides could increase the weight of chickens when incorporated into their diet. These authors concluded that "sulfasuxidine and streptomycin, single or in combination, lead to increased growth responses in chicks receiving our basal diet supplemented with adequate amounts of folic acid" (Moore et al., 1946).

The use of these antibiotics increases the conversion of feed into weight in these animals. The increase in weight of the treated animals may reach from 8 to 15\% (Butaye et al., 2003).

For a long time, the increase in both weight and size of animals treated with antibiotics added to their diet was attributed to the decrease in the appearance of subclinical infections, which would favor their growth (Braude et al., 1955; Griffin, 1980; De Wilde, 1984; Elwinger et al., 1998). In fact, what happens is a phenomenon called dysbiosis, characterized by the significant alteration of the intestinal microbiota of these animals, favoring the predominance of microorganisms with greater capacity of metabolization of foods which, as a consequence, will provide a higher amount of calories to the animal, favoring its increase in weight, especially fat (Raoult, 2008a; Thuny et al., 2010; Million et al., 2012). It is important to remember that the classes of antibiotics most used to promote growth in animals are tetracyclines, macrolides, and penicillins, the very same classes used in human beings.

These antibiotics, in small amounts, reach humans either via consumption of the meat of these animals or by the immense amount of such drugs deposited in the soil. The Food and Drug Administration reported that, in 2011, 13500 tons of antibiotics were used for the production of animal proteins through raising cattle, poultry and pigs (Riley et al., 2013). Taking into account that ca. $75 \%$ of these antibiotics administered to animals are not absorbed, being eliminated via feces and urine, there are around 10 million kilograms of antibiotics dumped annually into the environment only by the feces and urine of these animals (CheeSanford et al., 2009). It is important to remember that antibiotics also reach the environment via spraying of crops (McManus et al., 2002), as well as via hospital wastewaters and overdue medicines that reach our rivers, contaminating the public water supply with small, yet detectable, concentrations of antibiotics (Kulkarni et al., 2017; Szekeres et al., 2017).

At a planetary scale, these numbers are even more worrying. Data from The State of the World's Antibiotics 2015 allows to conclude that out of a total of 100000 tons of antibiotics produced worldwide, 65000 tons were used in animal production (Singer et al., 2016).

By making a rough calculation, estimating the world population at 7.2 billion human beings (World Population, 2017) and a worldwide production of antibiotics in the order of 100000 tons $\left(10^{11} \mathrm{~g}\right)$, one obtains as a final result the absurd value of $13.8 \mathrm{~g}$ of antibiotic produced per year per inhabitant of our planet.

The exposure to agents that alter our microbiota has increased significantly in the last 80 years, whether as the form of treatments or prophylaxis, or even indirectly via consumption of foodstuff contaminated with these molecules, or even via the immense quantities dumped annually into our environment.

There is no doubt that our microbiota, exposed to 80 years of aggressions through antibiotics, is quite different from the microbiota of our grandparents and our ancestors (Blaser and Falkow, 2009).

Certainly, with a microbiota quite different from that of our ancestors, we have been metabolizing and utilizing our food during the digestive process in a very different way than we did hundreds (or even thousands) of years ago. Are there consequences of this?

\section{HUMAN MICROBIOTA AND ITS ROLE}

The human microbiota (called flora, until recently), especially the gut microbiota, has been the subject of hundreds of research studies aiming at shedding light on its role, its composition and the relationships that it establishes with its host (Alexander et al., 2017; Duranti et al., 2017; Koppel and Maini Rekdal, 2017; Mirzaei and Maurice, 2017; Thursby and Juge, 2017).

The intestinal microbiota is composed by ca. 100 trillion cells, including bacteria, fungi, viruses and other eukaryotic species. 
There are basically five major Phyla: Firmicutes, Bacteroidetes, Proteobacteria, Verrucomicrobia, and Actinobacteria (Yang and Kweon, 2016). The amount of microorganisms present in the human microbiota exceeds by more than 10 times the number of human cells integrating the human body (Goulet, 2015), and the genes carried by these trillions of microorganisms (called "microbioma") surpass by more than 100 times the human genome, bringing a symbiotic relationship and of co-existence between the human host and his "guests" (Sanz et al., 2010).

During our intrauterine life, our gastrointestinal tract is totally devoid of microbial life (and thus, practically sterile), although some authors claim that upon swallowing amniotic fluid by the fetus there would be the possibility of forming an intestinal "intrauterine" microbiota (DiGiulio et al., 2008). The microbiota is established by contact. Children born via cesarean birth are, however, deprived of such contact, not contaminating themselves with the mother's microbiota (Makino et al., 2013).

The human microbiota begins to develop from birth, by vertical transmission, upon contact of the baby with both the vaginal, fecal and cutaneous microbiota, and exposure to breast milk (Reinhardt et al., 2009). It develops with the contact with other family members, also suffering interference from the diet (Backhed et al., 2005), age (Agans et al., 2011), sex
(Markle et al., 2013), and geographical location (Grzeskowiak et al., 2012), and suffering also chemical and/or biological interference arising from exposure to antibiotics or probiotics. These interferents alter the microbiota most strongly until late childhood ( 3 years of age), time at which it stabilizes for the adult life (Vael et al., 2011).

The intestinal microbiota exerts numerous known functions: (a) trophic effect upon the intestinal epithelium, favoring the appearance of microvilli, which increases the capacity of nutrient absorption; (b) contributes to the homeostasis of the local immune system (Stappenbeck et al., 2002); (c) acts on the metabolization of indigestible polysaccharides, favoring the absorption of short chain fatty acids (SCFA) (Turnbaugh et al., 2006); and (d) regulates the intestinal transit, affecting the amount of energy absorbed from the diet (Vandeputte et al., 2016). All these functions, especially those related to metabolism and absorption, clearly show the fundamental role that the human microbiota exerts on its host's weight gain or loss.

Due to having established structure and organic functions, numerous authors already consider the human intestinal microbiota as a new (invisible) organ (Clarke et al., 2014; Pluznick, 2014; Goulet, 2015; O'Callaghan et al., 2016). Toivanen et al. (2001) compared the weight of the human microbiota

TABLE 1 | Epidemiological studies in children in the last 6 years, showing the relationship between the use of antibiotics and obesity.

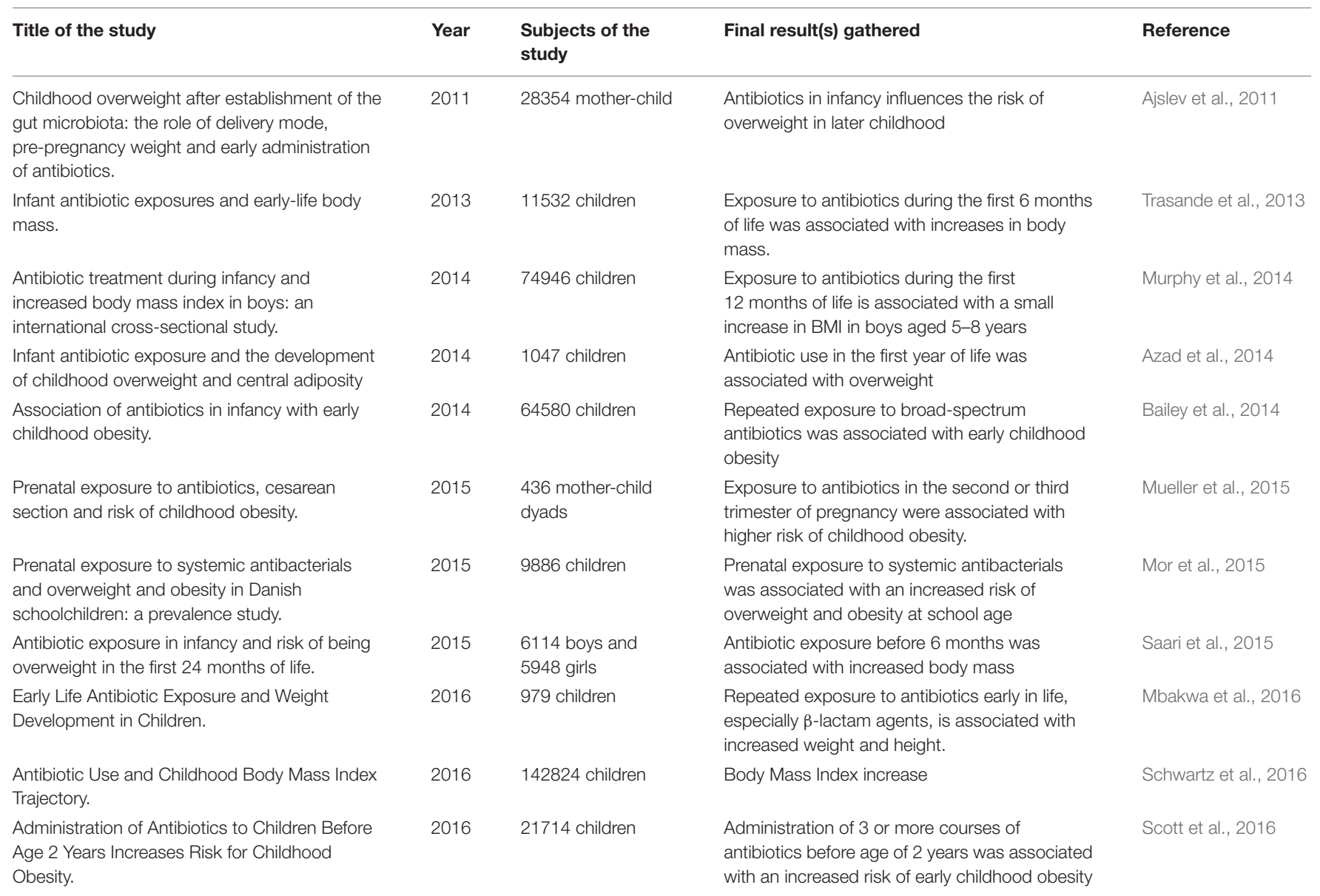


TABLE 2 | Percentage of obesity and antibiotic prescription rate in all American States. Data from 2014, sourced from the Centers for Disease Control and Prevention (CDC).

\begin{tabular}{|c|c|c|c|c|}
\hline American state & Obesity (\%) & Obesity rank & $\begin{array}{l}\text { Antibiotic prescription/ } \\
1000 \text { inhabitants }\end{array}$ & $\begin{array}{c}\text { Antibiotic } \\
\text { prescription rank }\end{array}$ \\
\hline Louisiana & 36.2 & 1 & 1177 & 4 \\
\hline Alabama & 35.6 & 2 & 1124 & 7 \\
\hline Mississippi & 35.6 & 3 & 1222 & 3 \\
\hline West Virginia & 35.6 & 4 & 1285 & 1 \\
\hline Kentucky & 34.6 & 5 & 1262 & 2 \\
\hline Arkansas & 34.5 & 6 & 1155 & 6 \\
\hline Kansas & 34.2 & 7 & 992 & 10 \\
\hline Oklahoma & 33.9 & 8 & 966 & 11 \\
\hline Tennessee & 33.8 & 9 & 1162 & 5 \\
\hline Missouri & 32.4 & 10 & 936 & 15 \\
\hline Texas & 32.4 & 11 & 899 & 21 \\
\hline lowa & 32.1 & 12 & 1001 & 9 \\
\hline South Carolina & 31.7 & 13 & 927 & 16 \\
\hline Nebraska & 31.4 & 14 & 1045 & 8 \\
\hline Indiana & 31.3 & 15 & 951 & 13 \\
\hline Michigan & 31.2 & 16 & 925 & 17 \\
\hline North Dakota & 31 & 17 & 853 & 26 \\
\hline Illinois & 30.8 & 18 & 853 & 25 \\
\hline Georgia & 30.7 & 19 & 841 & 28 \\
\hline Wisconsin & 30.7 & 20 & 745 & 34 \\
\hline South Dakota & 30.4 & 21 & 901 & 19 \\
\hline North Carolina & 30.1 & 22 & 861 & 24 \\
\hline Oregon & 30.1 & 23 & 570 & 49 \\
\hline Maine & 30 & 24 & 720 & 37 \\
\hline Pennsylvania & 30 & 25 & 886 & 23 \\
\hline Alaska & 29.8 & 26 & 502 & 50 \\
\hline Ohio & 29.8 & 27 & 965 & 12 \\
\hline Delaware & 29.7 & 28 & 938 & 14 \\
\hline Virginia & 29.2 & 29 & 799 & 29 \\
\hline Wyoming & 29 & 30 & 778 & 32 \\
\hline Maryland & 28.9 & 31 & 796 & 30 \\
\hline New Mexico & 28.8 & 32 & 714 & 38 \\
\hline Idaho & 28.6 & 33 & 693 & 42 \\
\hline Arizona & 28.4 & 34 & 740 & 35 \\
\hline Florida & 26.8 & 35 & 729 & 36 \\
\hline Nevada & 26.7 & 36 & 709 & 40 \\
\hline Washington & 26.4 & 37 & 600 & 47 \\
\hline New Hampshire & 26.3 & 38 & 702 & 41 \\
\hline Minnesota & 26.1 & 39 & 710 & 39 \\
\hline Rhode Island & 26 & 40 & 893 & 22 \\
\hline New Jersey & 25.6 & 41 & 903 & 18 \\
\hline Connecticut & 25.3 & 42 & 847 & 27 \\
\hline Vermont & 25.1 & 43 & 639 & 45 \\
\hline New York & 25 & 44 & 900 & 20 \\
\hline Utah & 24.5 & 45 & 783 & 31 \\
\hline Massachusetts & 24.3 & 46 & 769 & 33 \\
\hline California & 24.2 & 47 & 570 & 48 \\
\hline Montana & 23.6 & 48 & 648 & 43 \\
\hline Hawaii & 22.7 & 49 & 644 & 44 \\
\hline Colorado & 20.2 & 50 & 625 & 46 \\
\hline
\end{tabular}


(1.5 kg) with other organs such as liver $(1.5 \mathrm{~kg})$, brain $(1.4 \mathrm{~kg})$, lung $(0.84 \mathrm{~kg})$, and kidney $(0.27 \mathrm{~kg})$, thus shedding light upon the importance that this new (although invisible) organ represents to the human organism.

\section{HUMAN MICROBIOTA AND METABOLISM}

One of the major (and perhaps the most important) functions played by the intestinal microbiota is the metabolism of nutrients. In order to exert their function of withdrawing energy from the foodstuff consumed by their hosts, the microbiota produces enzymes such as glycoside hydrosilases and polysacharide lyases with the role of withdrawing energy from inaccessible foods (Villanueva-Millan et al., 2015).

The role of the microbiota in the uptake of energy from food, by transforming it into absorbable fat, has been elucidated in a more convincing manner by studies using germ-free animals. Regular animals, with normal microbiota, subjected to the same diet as their "germ-free" counterparts, accumulated more fat when compared to each other, contributing to the accumulation of fat in the former animals. The authors concluded their study by stating that "Our findings suggest that the gut microbiota is an

\section{A}

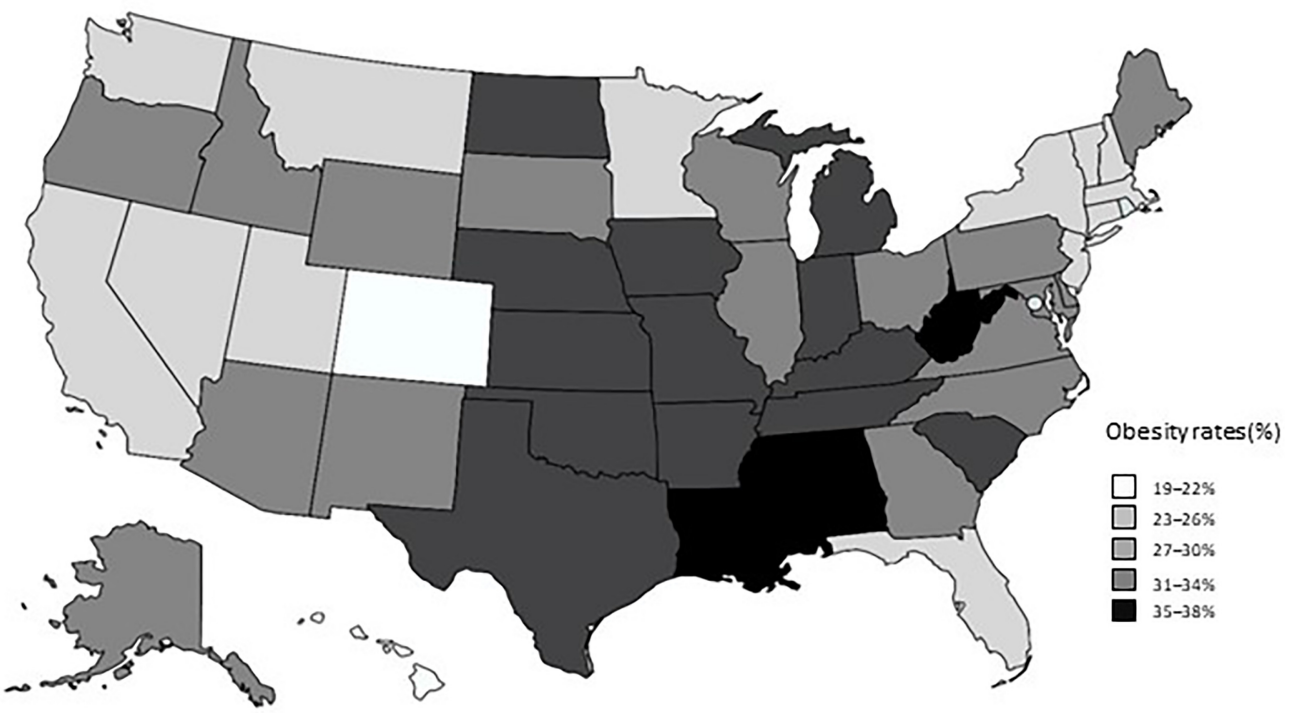

B

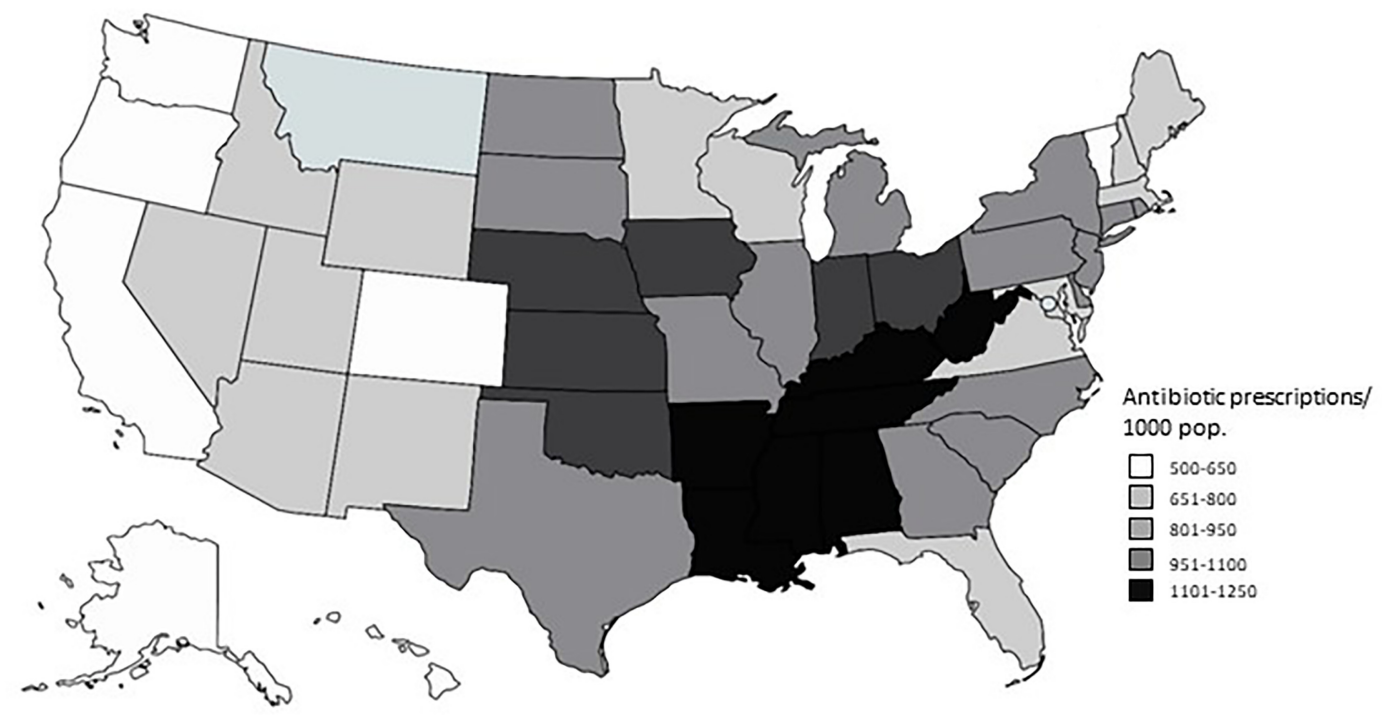

Crevted with map-chatnet

FIGURE 1 | American maps showing rates of obesity (A) and prescription of antibiotics (B) in the American States. Data from 2014, sourced from the Centers for Disease Control and Prevention (CDC). 
important environmental factor that affects energy harvest from the diet and energy storage in the host" (Backhed et al., 2004).

Indigestible oligosaccharides, such as oligofructose (inulin), are converted by the gut microbiota into monosaccharides which are then converted to SCFA (acetate, propionate, and butyrate), being then easily absorbed (Villanueva-Millan et al., 2015). The acetate and propionate formed are used by the liver for lipogenesis and gluconeogenesis. Butyrate has its role as energy source for colonic epithelial cells (Janssen and Kersten, 2015). The conversion of polysaccharides by microorganisms from the gut microbiota into SCFAs has been implicated as the factor responsible for the increased uptake of fat and concomitant obesity in human hosts (Greenblum et al., 2012; Woting and Blaut, 2016).

For many years obesity has been treated as a pandemic, with constant increases in the prevalence among adolescent and children, being considered a real threat to the human condition.(Katz, 2016) Worldwide, there are more than 2 billion individuals considered to be overweight or obese. The prevalence rate for these conditions increased $27.5 \%$ for adults and $47.1 \%$ for children between 1980 and 2013 (Ng et al., 2014).

The condition of obesity originates in multifactorial situations, including genetic (van der Klaauw and Farooqi, 2015), physiological (leptin modulation) (Bajzer and Seeley, 2006), heredity (Farooqi and O'Rahilly, 2006), socio-cultural behaviors among populations; such as geography, food preferences, physical activity, gender, age, etc (Williams et al., 2015).

Over the last few years, and because of all the personal and public health disorders caused by obesity, numerous studies have been published showing the relevant role of the gut microbiota in the development of obesity (Reinhardt et al., 2009; Zhang et al., 2009; Scarpellini et al., 2010; Boroni Moreira et al., 2012; BruceKeller et al., 2015; Cox and Blaser, 2015; Duranti et al., 2017; Isolauri, 2017; Raoult, 2017).

Some studies relate the change in the proportion of the phyla Firmicutes:Bacteroidetes as responsible for the change of weight gain/loss. Such studies indicate that the increase of the phylo Firmicutes in relation to the Bacteroidetes would be responsible for the increase in the absorption of calories from food, supplying larger amounts of fat to the host with concomitant increase in both its weight and fat mass (Ley et al., 2005; Compare et al., 2016; Koliada et al., 2017; Kvit and Kharchenko, 2017; Riva et al., 2017; Shang et al., 2017).

In this way, any disturbance in the microbiota (dysbiosis) may alter the Firmicutes:Bacteroidetes ratio, leading to a higher amount of Firmicutes and concomitant higher absorption of fats, increasing both the weight and the amount of fat of the host. These microbiota changes (dysbiosis) are caused by treatments with antibiotics, especially when administered before the first 3 years of life, even in small amounts and during short periods of time (Riley et al., 2013; Lu and Ni, 2015; Duranti et al., 2017; Isolauri, 2017).

\section{ANTIBIOTICS AND OBESITY}

Results from controlled epidemiological studies carried out in the last 6 years (see Table 1) involving 368360 children

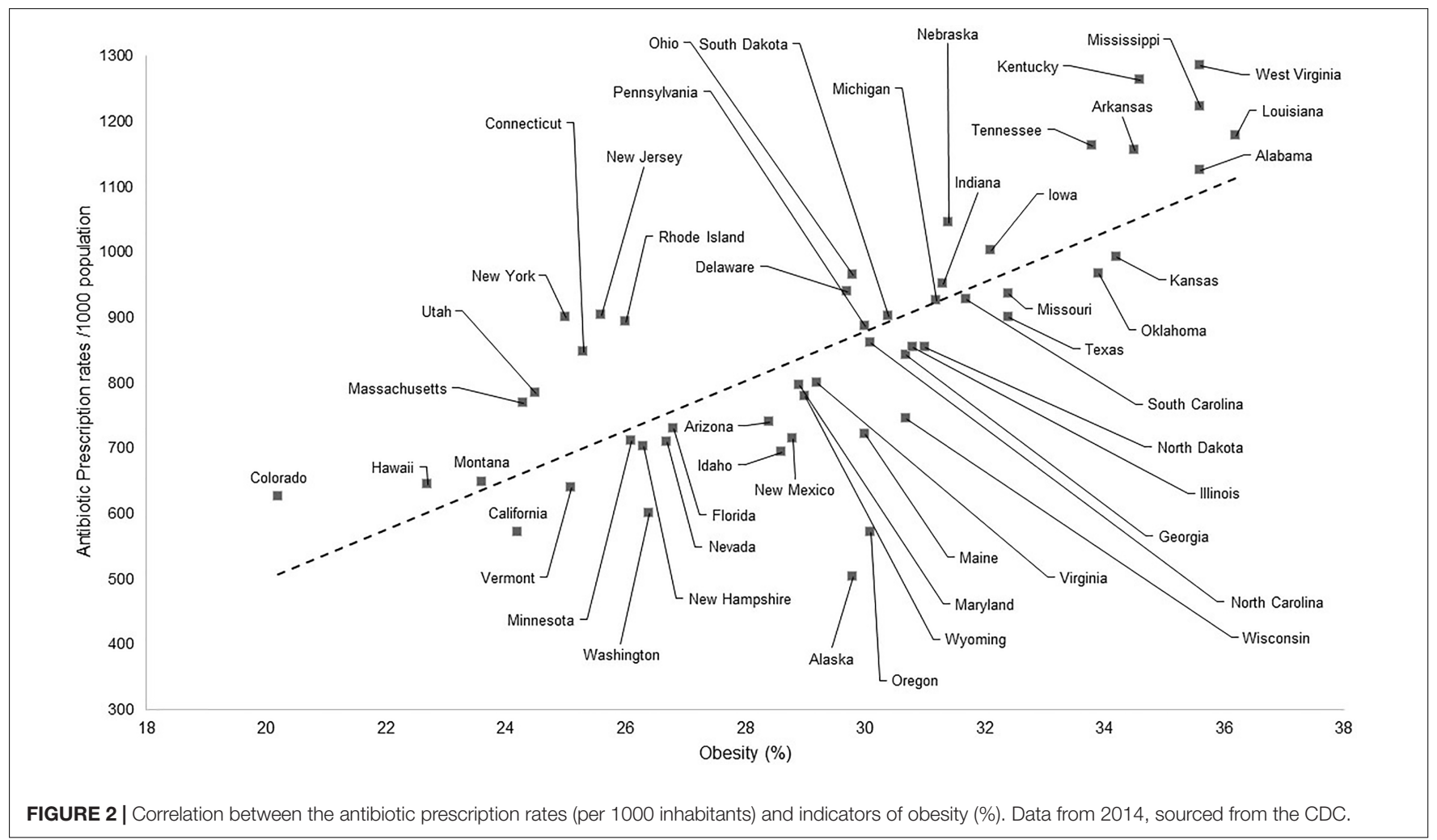


(sum of all studies) have always associated early-life (or even intrauterine) exposure to antibiotics with weight gain or BMI increase. It is important to emphasize that such association relates not the use of the antibiotic directly with obesity, but rather the antibiotic being the cause of the alteration of the microbiota (dysbiosis) and concomitant increase in the energy intake from the diet and consequent obesity.

Studies in germ-free animals that received a microbiota transplant and did not receive any antibiotics whatsoever, developed obesity without contact with antibiotics, thus proving that gut microbiota plays a fundamental role in the accumulation of fat. The antibiotic serves only to alter it (Backhed et al., 2004; Turnbaugh et al., 2006; Goodman et al., 2011; Kimura et al., 2013; Cox et al., 2014; Gerard, 2016). Studies carried out using regular animals (non-germ-free) that received antibiotics point to the same direction, increasing the weight of the animals due to changes in their gut microbiota (Cho et al., 2012; de Sa Del Fiol et al., 2014; Khan et al., 2016; Marciano et al., 2017).

The relationship between the use of antibiotics and the development of obesity has become increasingly more evident and apparent in human beings. Some authors have clearly established the relationship between the use of antibiotics in large-scale in the past 70 years and the "epidemic" of obesity that has occurred in parallel, almost as an adverse epidemiological effect (Ternak, 2005; Raoult, 2008b; Riley et al., 2013).

Data gathered from the CDC on Antibiotic Prescriptions Dispensed in United States. Community Pharmacies per 1000 inhabitants in 2014 show, on average, 835 antibiotic prescriptions dispensed per 1000 inhabitants (CDC, 2014). Such data, separated for the 50 individual American states, was compared with the obesity indicators of those same states (data also provided by the CDC) (CDC, 2015). The data on antibiotic prescriptions ( $\mathrm{n} / 1000$ people) and indication of obesity (\%) are displayed and compared in Table 2.

The results displayed in Table 2 exhibit a great similarity between the use of antibiotics in the United States and the indicators of obesity. When Pearson's correlation coefficient is applied, a result of 0.76 is obtained which is considered a positive and strong correlation, meaning that the higher the

\section{REFERENCES}

Agans, R., Rigsbee, L., Kenche, H., Michail, S., Khamis, H. J., and Paliy, O. (2011). Distal gut microbiota of adolescent children is different from that of adults. FEMS Microbiol. Ecol. 77, 404-412. doi: 10.1111/j.1574-6941.2011. 01120.x

Ajslev, T. A., Andersen, C. S., Gamborg, M., Sorensen, T. I., and Jess, T. (2011). Childhood overweight after establishment of the gut microbiota: the role of delivery mode, pre-pregnancy weight and early administration of antibiotics. Int. J. Obes. 35, 522-529. doi: 10.1038/ijo.2011.27

Alexander, J. L., Wilson, I. D., Teare, J., Marchesi, J. R., Nicholson, J. K., and Kinross, J. M. (2017). Gut microbiota modulation of chemotherapy efficacy and toxicity. Genes Nutr. 14, 356-365. doi: 10.1038/nrgastro.2017.20

Andersson, D. I., and Hughes, D. (2014). Microbiological effects of sublethal levels of antibiotics. Nat. Rev. Microbiol. 12, 465-478. doi: 10.1038/nrmicro3270 use of antibiotics the higher the rate of obesity at that place (Mukaka, 2012). The indexes of obesity (CDC, 2015) and of use of antibiotics (CDC, 2014) are plotted in Figure 1.

In the same way, however, by illustrating the data in a graphical fashion one can perceive much similarity between the data on obesity and the use of antibiotics, shown on the maps of the United States (see Figure 2).

\section{CONCLUSION}

The answer to the title of this short review paper seems to be YES. The scientific community has reached a consensus on the relationship between antibiotics and obesity, showing beyond any doubt that the use of antibiotics causes dysbiosis to varying degrees, especially in children (with less than 3 years of age), which can trigger an increased energy intake from the diet with concomitant increase of weight.

There is no doubt whatsoever that antibiotics have been, and still are, drugs with vital importance in the fight against bacterial infections. However, the need for prudent and rational use of antibiotics is more and more clear so as to avoid both collective health problems (increase in bacterial resistance to these antimicrobial drugs) and individual health problems (increase in weight).

The alternative for replacing the microbiota with probiotics seems to be an important strategy for the safe use of antibiotics to fight bacterial infections in children, without the associated risk of dysbiosis and concomitant increase in body weight.

It is the vital role of the health-care professionals to orient both themselves and their patients toward the correct and prudent use of antibiotics, and to wait until further scientific studies enlighten even more the relationship between antibiotics, dysbiosis, and obesity.

\section{AUTHOR CONTRIBUTIONS}

FDF, VB, SB-F, LCL, and CB designed the study, involved in the selection and reading of the review articles, prepared the manuscript, and discussed the results and conclusion.

Azad, M. B., Bridgman, S. L., Becker, A. B., and Kozyrskyj, A. L. (2014). Infant antibiotic exposure and the development of childhood overweight and central adiposity. Int. J. Obes. 38, 1290-1298. doi: 10.1038/ijo.2014.119

Backhed, F., Ding, H., Wang, T., Hooper, L. V., Koh, G. Y., Nagy, A., et al. (2004). The gut microbiota as an environmental factor that regulates fat storage. Proc. Natl. Acad. Sci. U.S.A. 101, 15718-15723. doi: 10.1073/pnas.0407076101

Backhed, F., Ley, R. E., Sonnenburg, J. L., Peterson, D. A., and Gordon, J. I. (2005). Host-bacterial mutualism in the human intestine. Science 307, 1915-1920. doi: $10.1126 /$ science. 1104816

Bailey, L. C., Forrest, C. B., Zhang, P., Richards, T. M., Livshits, A., and DeRusso, P. A. (2014). Association of antibiotics in infancy with early childhood obesity. JAMA Pediatr. 168, 1063-1069. doi: 10.1001/jamapediatrics.2014. 1539

Bajzer, M., and Seeley, R. J. (2006). Physiology: obesity and gut flora. Nature 444, 1009-1010. doi: 10.1038/4441009a 
Blaser, M. J., and Falkow, S. (2009). What are the consequences of the disappearing human microbiota? Nat. Rev. Microbiol. 7, 887-894. doi: 10.1038/nrmicro 2245

Boroni Moreira, A. P., Fiche Salles Teixeira, T., do C Gouveia Peluzio, M., and de Cassia Goncalves Alfenas, R. (2012). Gut microbiota and the development of obesity. Nutr. Hosp. 27, 1408-1414. doi: 10.3305/nh.2012.27.5.5887

Braude, R., Campbell, R. C., Lucas, I. A., Luscombe, J. R., Robinson, K. L., and Taylor, J. H. (1955). Antibiotics and endocrine stimulants as promoters of growth in fattening pigs. Br. J. Nutr. 9, 191-196. doi: 10.1079/BJN195 50027

Broe, A., Pottegard, A., Lamont, R. F., Jorgensen, J. S., and Damkier, P. (2014). Increasing use of antibiotics in pregnancy during the period 2000-2010: prevalence, timing, category, and demographics. BJOG 121, 988-996. doi: 10. 1111/1471-0528.12806

Bruce-Keller, A. J., Salbaum, J. M., Luo, M., Blanchard, E. IV, Taylor, C. M., Welsh, D. A., et al. (2015). Obese-type gut microbiota induce neurobehavioral changes in the absence of obesity. Biol. Psychiatry 77, 607-615. doi: 10.1016/j.biopsych. 2014.07.012

Butaye, P., Devriese, L. A., and Haesebrouck, F. (2003). Antimicrobial growth promoters used in animal feed: effects of less well known antibiotics on grampositive bacteria. Clin. Microbiol. Rev. 16, 175-188. doi: 10.1128/CMR.16.2.175188.2003

CDC (2014). Centers for Disease Control, and Prevention. Antibiotic Prescriptions Dispensed in U. S. Community Pharmacies Per. (1000)Population. Available at: https://gis.cdc.gov/grasp/PSA/AUMapView.html

CDC (2015). Centers for Disease Control and Prevention Prevalence of SelfReported Obesity Among U.S. Adults by State and Territory, Behavioral Risk Factor Surveillance System. Available at: https:/www.cdc.gov/obesity/data/ prevalence-maps.html

Chee-Sanford, J. C., Mackie, R. I., Koike, S., Krapac, I. G., Lin, Y. F., Yannarell, A. C., et al. (2009). Fate and transport of antibiotic residues and antibiotic resistance genes following land application of manure waste. J. Environ. Qual. 38, 1086-1108. doi: 10.2134/jeq2008.0128

Cho, I., Yamanishi, S., Cox, L., Methe, B. A., Zavadil, J., Li, K., et al. (2012). Antibiotics in early life alter the murine colonic microbiome and adiposity. Nature 488, 621-626. doi: 10.1038/nature11400

Cima, G. (2014). WHO warns of 'post-antibiotic era'. J. Am. Vet. Med. Assoc. 244, 1356-1357.

Clarke, G., Stilling, R. M., Kennedy, P. J., Stanton, C., Cryan, J. F., and Dinan, T. G. (2014). Minireview: gut microbiota: the neglected endocrine organ. Mol. Endocrinol. 28, 1221-1238. doi: 10.1210/me.2014-1108

Compare, D., Rocco, A., Sanduzzi Zamparelli, M., and Nardone, G. (2016). The gut bacteria-driven obesity development. Dig. Dis. 34, 221-229. doi: 10.1159/ 000443356

Cox, L. M., and Blaser, M. J. (2015). Antibiotics in early life and obesity. Nat. Rev. Endocrinol. 11, 182-190. doi: 10.1038/nrendo.2014.210

Cox, L. M., Yamanishi, S., Sohn, J., Alekseyenko, A. V., Leung, J. M., Cho, I., et al. (2014). Altering the intestinal microbiota during a critical developmental window has lasting metabolic consequences. Cell 158, 705-721. doi: 10.1016/j. cell.2014.05.052

de Sa Del Fiol, F., Tardelli Ferreira, A. C., Marciano, J. J., Marques, M. C., and Sant'Ana, L. L. (2014). Obesity and the use of antibiotics and probiotics in rats. Chemotherapy 60, 162-167. doi: 10.1159/000371737

De Wilde, R. O. (1984). Comparison of virginiamycin and salinomycin as growth promoters in growing-fattening pigs. Dtsch. Tierarztl. Wochenschr. 91, 22-24.

DiGiulio, D. B., Romero, R., Amogan, H. P., Kusanovic, J. P., Bik, E. M., Gotsch, F., et al. (2008). Microbial prevalence, diversity and abundance in amniotic fluid during preterm labor: a molecular and culture-based investigation. PLoS One 3:e3056. doi: 10.1371/journal.pone.0003056

Donoghue, D. J. (2003). Antibiotic residues in poultry tissues and eggs: human health concerns? Poult. Sci. 82, 618-621.

Duranti, S., Ferrario, C., van Sinderen, D., Ventura, M., and Turroni, F. (2017). Obesity and microbiota: an example of an intricate relationship. Science 12:18. doi: 10.1186/s12263-017-0566-2

Ebell, M. H., and Radke, T. (2015). Antibiotic use for viral acute respiratory tract infections remains common. Am. J. Manag. Care 21, e567-e575.

Elwinger, K., Berndtson, E., Engstrom, B., Fossum, O., and Waldenstedt, L. (1998). Effect of antibiotic growth promoters and anticoccidials on growth of
Clostridium perfringens in the caeca and on performance of broiler chickens. Acta Vet. Scand. 39, 433-441.

Farooqi, S., and O'Rahilly, S. (2006). Genetics of obesity in humans. Endocr. Rev. 27, 710-718. doi: 10.1210/er.2006-0040

Fauci, A. S., and Marston, I. D. (2014). The perpetual challenge of antimicrobial resistance. JAMA 311, 1853-1854. doi: 10.1001/jama.2014.2465

Gerard, P. (2016). Gut microbiota and obesity. Cell. Mol. Life Sci. 73, 147-162. doi: 10.1007/s00018-015-2061-5

Goodman, A. L., Kallstrom, G., Faith, J. J., Reyes, A., Moore, A., Dantas, G., et al. (2011). Extensive personal human gut microbiota culture collections characterized and manipulated in gnotobiotic mice. Proc. Natl. Acad. Sci. U.S.A. 108, 6252-6257. doi: 10.1073/pnas. 1102938108

Goulet, O. (2015). Potential role of the intestinal microbiota in programming health and disease. Nutr. Rev. 73(Suppl. 1), 32-40. doi: 10.1093/nutrit/ nuv039

Greenblum, S., Turnbaugh, P. J., and Borenstein, E. (2012). Metagenomic systems biology of the human gut microbiome reveals topological shifts associated with obesity and inflammatory bowel disease. Proc. Natl. Acad. Sci. U.S.A. 109, 594-599. doi: 10.1073/pnas.1116053109

Griffin, R. M. (1980). The response of cage-reared cockerels to dietary medication with growth promoters. I. Size and consistency of the response. Poult. Sci. 59, 412-416. doi: 10.3382/ps.0590412

Grzeskowiak, L., Collado, M. C., Mangani, C., Maleta, K., Laitinen, K., Ashorn, P., et al. (2012). Distinct gut microbiota in southeastern African and northern European infants. J. Pediatr. Gastroenterol. Nutr. 54, 812-816. doi: 10.1097/ MPG.0b013e318249039c

Hawker, J. I., Smith, S., Smith, G. E., Morbey, R., Johnson, A. P., Fleming, D. M., et al. (2014). Trends in antibiotic prescribing in primary care for clinical syndromes subject to national recommendations to reduce antibiotic resistance, UK 1995-2011: analysis of a large database of primary care consultations. J. Antimicrob. Chemother. 69, 3423-3430. doi: 10.1093/jac/dku291

Higashi, T., and Fukuhara, S. (2009). Antibiotic prescriptions for upper respiratory tract infection in Japan. Intern. Med. 48, 1369-1375. doi: 10.2169/ internalmedicine.48.1893

Isolauri, E. (2017). Microbiota and Obesity. Nestle Nutr. Inst. Workshop Ser. 88, 95-105. doi: 10.1159/000455217

Janssen, A. W., and Kersten, S. (2015). The role of the gut microbiota in metabolic health. FASEB J. 29, 3111-3123. doi: 10.1096/fj.14-269514

Katz, D. L. (2016). The mass of humanity and the weight of the world: obesity and the environment at a confluence of causes. Curr. Obes. Rep. 5, 386-388. doi: 10.1007/s13679-016-0236-5

Khan, I., Azhar, E. I., Abbas, A. T., Kumosani, T., Barbour, E. K., Raoult, D., et al. (2016). Metagenomic analysis of antibiotic-induced changes in gut microbiota in a pregnant rat model. Front. Pharmacol. 7:104. doi: 10.3389/fphar.2016. 00104

Kimura, I., Ozawa, K., Inoue, D., Imamura, T., Kimura, K., Maeda, T., et al. (2013). The gut microbiota suppresses insulin-mediated fat accumulation via the short-chain fatty acid receptor GPR43. Nat. Commun. 4:1829. doi: 10.1038/ ncomms 2852

Koliada, A., Syzenko, G., Moseiko, V., Budovska, L., Puchkov, K., Perederiy, V., et al. (2017). Association between body mass index and Firmicutes/Bacteroidetes ratio in an adult Ukrainian population. BMC Microbiol. 17:120. doi: 10.1186/s12866-017-1027-1

Koppel, N., and Maini Rekdal, V. (2017). Chemical transformation of xenobiotics by the human gut microbiota. Science 356:eaag2770. doi: 10.1126/science. aag2770

Kronman, M. P., Zhou, C., and Mangione-Smith, R. (2014). Bacterial prevalence and antimicrobial prescribing trends for acute respiratory tract infections. Pediatrics 134, e956-e965. doi: 10.1542/peds.2014-0605

Kulkarni, P., Olson, N. D., Raspanti, G. A., Rosenberg Goldstein, R. E., Gibbs, S. G., Sapkota, A., et al. (2017). Antibiotic concentrations decrease during wastewater treatment but persist at low levels in reclaimed water. Int. J. Environ. Res. Public Health 14:668. doi: 10.3390/ijerph14060668

Kvit, K. B., and Kharchenko, N. V. (2017). Gut microbiota changes as a risk factor for obesity. Wiad. Lek. 70, 231-235.

Ley, R. E., Backhed, F., Turnbaugh, P., Lozupone, C. A., Knight, R. D., and Gordon, J. I. (2005). Obesity alters gut microbial ecology. Proc. Natl. Acad. Sci. U.S.A. 102, 11070-11075. doi: 10.1073/pnas.0504978102 
Lu, C. Y., and Ni, Y. H. (2015). Gut microbiota and the development of pediatric diseases. J. Gastroenterol. 50, 720-726. doi: 10.1007/s00535-015-1082-z

Makino, H., Kushiro, A., Ishikawa, E., Kubota, H., Gawad, A., Sakai, T., et al. (2013). Mother-to-infant transmission of intestinal bifidobacterial strains has an impact on the early development of vaginally delivered infant's microbiota. PLoS One 8:e78331. doi: 10.1371/journal.pone.0078331

Marciano, J. J., de Sá Del Fiol, F., Ferreira, A. C. M. T., Marques, M. C., and Santana, L. L. (2017). Changes in weight and body fat after use of tetracycline and Lactobacillus gasseri in rats. Braz. J. Pharm. Sci. 53:e16059. doi: 10.1590/ s2175-97902017000116059

Markle, J. G., Frank, D. N., Mortin-Toth, S., Robertson, C. E., Feazel, L. M., Rolle-Kampczyk, U., et al. (2013). Sex differences in the gut microbiome drive hormone-dependent regulation of autoimmunity. Science 339, 1084-1088. doi: $10.1126 /$ science. 1233521

Mbakwa, C. A., Scheres, L., Penders, J., Mommers, M., Thijs, C., and Arts, I. C. (2016). Early life antibiotic exposure and weight development in children. J. Pediatr. 176, 105-113.e2. doi: 10.1016/j.jpeds.2016.06.015

McManus, P. S., Stockwell, V. O., Sundin, G. W., and Jones, A. L. (2002). Antibiotic use in plant agriculture. Annu. Rev. Phytopathol. 40, 443-465. doi: 10.1146/ annurev.phyto.40.120301.093927

Million, M., Angelakis, E., Paul, M., Armougom, F., Leibovici, L., and Raoult, D. (2012). Comparative meta-analysis of the effect of Lactobacillus species on weight gain in humans and animals. Microb. Pathog. 53, 100-108. doi: 10.1016/ j.micpath.2012.05.007

Mirzaei, M. K., and Maurice, C. F. (2017). Menage a trois in the human gut: interactions between host, bacteria and phages. Nat. Rev. Microbiol. 15, 397408. doi: 10.1038/nrmicro.2017.30

Moore, P. R., Evenson, A., Luckey, T. D., McCoy, E., Elvehjem, C. A., and Hart, E. B. (1946). Use of sulfasuxidine, streptothricin, and streptomycin in nutritional studies with the chick. J. Biol. Chem. 165, 437-441.

Mor, A., Antonsen, S., Kahlert, J., Holsteen, V., Jorgensen, S., Holm-Pedersen, J., et al. (2015). Prenatal exposure to systemic antibacterials and overweight and obesity in Danish schoolchildren: a prevalence study. Int. J. Obes. 39, 1450-1455. doi: 10.1038/ijo.2015.129

Mueller, N. T., Whyatt, R., Hoepner, L., Oberfield, S., Dominguez-Bello, M. G., Widen, E. M., et al. (2015). Prenatal exposure to antibiotics, cesarean section and risk of childhood obesity. Int. J. Obes. 39, 665-670. doi: 10.1038/ijo. 2014.180

Mukaka, M. (2012). A guide to appropriate use of Correlation coefficient in medical research. Malawi Med. J. 24, 69-71.

Murphy, R., Stewart, A. W., Braithwaite, I., Beasley, R., Hancox, R. J., and Mitchell, E. A. (2014). Antibiotic treatment during infancy and increased body mass index in boys: an international cross-sectional study. Int. J. Obes. 38, 1115-1119. doi: 10.1038/ijo.2013.218

Ng, M., Fleming, T., Robinson, M., Thomson, B., Graetz, N., Margono, C., et al. (2014). Global, regional, and national prevalence of overweight and obesity in children and adults during 1980-2013: a systematic analysis for the Global Burden of Disease Study 2013. Lancet 384, 766-781. doi: 10.1016/S01406736(14)60460-8

O'Callaghan, T. F., Ross, R. P., Stanton, C., and Clarke, G. (2016). The gut microbiome as a virtual endocrine organ with implications for farm and domestic animal endocrinology. Domest. Anim. Endocrinol. 56(Suppl.), S44S55. doi: 10.1016/j.domaniend.2016.05.003

Pluznick, J. L. (2014). Gut microbes and host physiology: what happens when you host billions of guests? Front. Endocrinol. 5:91. doi: 10.3389/fendo.2014.00091

Raoult, D. (2008a). Human microbiome: take-home lesson on growth promoters? Nature 454, 690-691. doi: 10.1038/454690c

Raoult, D. (2008b). Obesity pandemics and the modification of digestive bacterial flora. Eur. J. Clin. Microbiol. Infect. Dis. 27, 631-634. doi: 10.1007/s10096-008$0490-\mathrm{x}$

Raoult, D. (2017). Microbiota, obesity and malnutrition. Genes Nutr. 106, 1-2. doi: 10.1016/j.micpath.2016.02.001

Reinhardt, C., Reigstad, C. S., and Backhed, F. (2009). Intestinal microbiota during infancy and its implications for obesity. J. Pediatr. Gastroenterol. Nutr. 48, 249-256. doi: 10.1097/MPG.0b013e318183187c

Riley, L. W., Raphael, E., and Faerstein, E. (2013). Obesity in the United States - dysbiosis from exposure to low-dose antibiotics? Front. Public Health 1:69. doi: $10.3389 /$ fpubh.2013.00069
Riva, A., Borgo, F., Lassandro, C., Verduci, E., Morace, G., Borghi, E., et al. (2017). Pediatric obesity is associated with an altered gut microbiota and discordant shifts in Firmicutes populations. Environ. Microbiol. 19, 95-105. doi: 10.1111/ $1462-2920.13463$

Saari, A., Virta, L. J., Sankilampi, U., Dunkel, L., and Saxen, H. (2015). Antibiotic exposure in infancy and risk of being overweight in the first 24 months of life. Pediatrics 135, 617-626. doi: 10.1542/peds.2014-3407

Sanz, Y., Santacruz, A., and Gauffin, P. (2010). Gut microbiota in obesity and metabolic disorders. Proc. Nutr. Soc. 69, 434-441. doi: 10.1017/ S0029665110001813

Scarpellini, E., Campanale, M., Leone, D., Purchiaroni, F., Vitale, G., Lauritano, E. C., et al. (2010). Gut microbiota and obesity. Intern. Emerg. Med. 5(Suppl. 1), S53-S56. doi: 10.1007/s11739-010-0450-1

Schwartz, B. S., Pollak, J., Bailey-Davis, L., Hirsch, A. G., Cosgrove, S. E., Nau, C., et al. (2016). Antibiotic use and childhood body mass index trajectory. Int. J. Obes. 40, 615-621. doi: 10.1038/ijo.2015.218

Scott, F. I., Horton, D. B., Mamtani, R., Haynes, K., Goldberg, D. S., Lee, D. Y., et al. (2016). Administration of antibiotics to children before age 2 years increases risk for childhood obesity. Gastroenterology 151, 120.e-129.e. doi: 10.1053/j. gastro.2016.03.006

Shang, Y., Khafipour, E., Derakhshani, H., Sarna, L. K., Woo, C. W., Siow, Y. L., et al. (2017). Short term high fat diet induces obesity-enhancing changes in mouse gut microbiota that are partially reversed by cessation of the high fat diet. Lipids 52, 499-511. doi: 10.1007/s11745-017-4253-2

Singer, A. C., Shaw, H., Rhodes, V., and Hart, A. (2016). Review of antimicrobial resistance in the environment and its relevance to environmental regulators. Front. Microbiol. 7:1728. doi: 10.3389/fmicb.2016.01728

Stappenbeck, T. S., Hooper, L. V., and Gordon, J. I. (2002). Developmental regulation of intestinal angiogenesis by indigenous microbes via Paneth cells. Proc. Natl. Acad. Sci. U.S.A. 99, 15451-15455. doi: 10.1073/pnas.202604299

Szekeres, E., Baricz, A., Chiriac, C. M., Farkas, A., Opris, O., Soran, M. L., et al. (2017). Abundance of antibiotics, antibiotic resistance genes and bacterial community composition in wastewater effluents from different Romanian hospitals. Environ. Pollut. 225, 304-315. doi: 10.1016/j.envpol.2017.01.054

Ternak, G. (2005). Antibiotics may act as growth/obesity promoters in humans as an inadvertent result of antibiotic pollution? Med. Hypotheses 64, 14-16. doi: 10.1016/j.mehy.2004.08.003

Thuny, F., Richet, H., Casalta, J. P., Angelakis, E., Habib, G., and Raoult, D. (2010). Vancomycin treatment of infective endocarditis is linked with recently acquired obesity. PLoS One 5:e9074. doi: 10.1371/journal.pone.0009074

Thursby, E., and Juge, N. (2017). Introduction to the human gut microbiota. Biochem. J. 474, 1823-1836. doi: 10.1042/BCJ20160510

Toivanen, P., Vaahtovuo, J., and Eerola, E. (2001). Influence of major histocompatibility complex on bacterial composition of fecal flora. Infect. Immun. 69, 2372-2377. doi: 10.1128/IAI.69.4.2372-2377.2001

Trasande, L., Blustein, J., Liu, M., Corwin, E., Cox, L. M., and Blaser, M. J. (2013). Infant antibiotic exposures and early-life body mass. Int. J. Obes. 37, 16-23. doi: 10.1038/ijo.2012.132

Turnbaugh, P. J., Ley, R. E., Mahowald, M. A., Magrini, V., Mardis, E. R., and Gordon, J. I. (2006). An obesity-associated gut microbiome with increased capacity for energy harvest. Nature 444, 1027-1031. doi: 10.1038/nature05414

Vael, C., Verhulst, S. L., Nelen, V., Goossens, H., and Desager, K. N. (2011). Intestinal microflora and body mass index during the first three years of life: an observational study. Gut Pathog. 3:8. doi: 10.1186/1757-4749-3-8

van der Klaauw, A. A., and Farooqi, I. S. (2015). The hunger genes: pathways to obesity. Cell 161, 119-132. doi: 10.1016/j.cell.2015.03.008

Vandeputte, D., Falony, G., Vieira-Silva, S., Tito, R. Y., Joossens, M., and Raes, J. (2016). Stool consistency is strongly associated with gut microbiota richness and composition, enterotypes and bacterial growth rates. Gut 65, 57-62. doi: 10.1136/gutjnl-2015-309618

Venkatesan, A. K., and Halden, R. U. (2014). Wastewater treatment plants as chemical observatories to forecast ecological and human health risks of manmade chemicals. Sci. Rep. 4:3731. doi: 10.1038/srep03731

Villanueva-Millan, M. J., Perez-Matute, P., and Oteo, J. A. (2015). Gut microbiota: a key player in health and disease. A review focused on obesity. J. Physiol. Biochem. 71, 509-525. doi: 10.1007/s13105-015-0390-3

Williams, E. P., Mesidor, M., Winters, K., Dubbert, P. M., and Wyatt, S. B. (2015). Overweight and obesity: prevalence, consequences, and causes of a growing 
public health problem. Curr. Obes. Rep. 4, 363-370. doi: 10.1007/s13679-0150169-4

World Population (2017). Wikipedia 2017. Available at: https://en.wikipedia.org/ wiki/World_population

Woting, A., and Blaut, M. (2016). The intestinal microbiota in metabolic disease. Nutrients 8:202. doi: 10.3390/nu8040202

Yang, J. Y., and Kweon, M. N. (2016). The gut microbiota: a key regulator of metabolic diseases. BMB Rep. 49, 536-541. doi: 10.5483/BMBRep.2016.49. 10.144

Yang, S., and Carlson, K. (2003). Evolution of antibiotic occurrence in a river through pristine, urban and agricultural landscapes. Water Res. 37, 4645-4656. doi: 10.1016/S0043-1354(03)00399-3

Zaffiri, L., Gardner, J., and Toledo-Pereyra, L. H. (2012). History of antibiotics. From salvarsan to cephalosporins. J. Invest. Surg. 25, 67-77. doi: 10.3109/ 08941939.2012.664099
Zhang, H., DiBaise, J. K., Zuccolo, A., Kudrna, D., Braidotti, M., Yu, Y., et al. (2009). Human gut microbiota in obesity and after gastric bypass. Proc. Natl. Acad. Sci. U.S.A. 106, 2365-2370. doi: 10.1073/pnas.0812600106

Conflict of Interest Statement: The authors declare that the research was conducted in the absence of any commercial or financial relationships that could be construed as a potential conflict of interest.

Copyright $\odot 2018$ Del Fiol, Balcão, Barberato-Fillho, Lopes and Bergamaschi. This is an open-access article distributed under the terms of the Creative Commons Attribution License (CC BY). The use, distribution or reproduction in other forums is permitted, provided the original author(s) and the copyright owner(s) are credited and that the original publication in this journal is cited, in accordance with accepted academic practice. No use, distribution or reproduction is permitted which does not comply with these terms. 